\section{A calculation model for liquid-liquid extraction of protactinium by 2,6-dimethyl-4-heptanol}

\begin{abstract}
Reprocessing of spent nuclear fuel usually employs the solvent extraction technique to recover fissile material, isolate other valuable radionuclides, recover precious metals, and remove contaminants. Efficient recovery of these species from highly radioactive solutions requires a detailed understanding of reaction conditions and metal speciation that leads to their isolation in pure forms. Due to the complex nature of these systems, identification of ideal reaction conditions for the efficient extraction of specific metals can be challenging. Thus, the development of experimental approaches that have the potential to reduce the number of experiments required to identify ideal conditions are desirable. In this study, a full-factorial experimental design was used to identify the main effects and variable interactions of three chemical parameters on the extraction of protactinium $(\mathrm{Pa})$. Specifically we investigated the main effects of the anion concentration $\left(\mathrm{NO}_{3}, \mathrm{Cl}^{-}\right)$extractant concentration, and solution acidity on the overall extraction of protactinium by 2,6-dimethyl-4-heptanol (diisobutylcarbinol; DIBC) from both $\mathrm{HCl}$ and $\mathrm{HNO}_{3}$ solutions. Our results indicate that in $\mathrm{HCl}$, the extraction of protactinium was dominated by the solution acidity, while in nitric acid the extraction was strongly effected by the [DIBC]. Based on our results, a mathematical model was derived, that describes the relationship between concentrations of anions, extractant, and solution acidity and the expected values of Pa distribution coefficients in both $\mathrm{HCl}$ and $\mathrm{HNO}_{3}$. This study demonstrates the potential to predict the distribution coefficient values, based upon a mathematical model generated by a full-factorial experimental design.
\end{abstract}

Key words: design of experiments $\bullet$ protactinium $\bullet$ solvent extraction

A. W. Knight, E. S. Eitrheim

Department of Chemistry, E373 CB,

The University of Iowa,

Iowa City, IA 52246, USA

\section{A. W. Nelson}

Interdisciplinary Human Toxicology Program, E373 CB,

The University of Iowa,

Iowa City, IA 52246, USA

\section{K. Schultz ${ }^{凶}$}

Department of Chemistry, E373 CB,

The University of Iowa,

Iowa City, IA 52246, USA

and Interdisciplinary Human Toxicology Program,

E373 CB

The University of Iowa,

IA 52246, USA

and Departments of Radiology and Radiation Oncology

(Free Radical and Radiation Biology Program),

The University of Iowa,

ML B180 FRRB, 500 Newton Road,

Iowa City, IA 52246, USA,

Tel.: +1 319 335-8017,

E-mail: Michael-schultz@uiowa.edu

Received: 1 July 2015

Accepted: 26 September 2015

\section{Introduction}

Separation and isolation of long-lived radionuclides from aqueous solutions is critical to efficient high-level nuclear-waste management [1]. Due to the nature of nuclear-fission energy production, waste products contain a wide range of radionuclides including: fission products, actinides, and their radioactive decay products $[1,2]$. Separation and isolation of various elements from the nuclear waste are performed to improve the long-term stability of the waste [2]; recycle unused fuel, and recover precious metals contained in the waste stream [3, 4]. Since this process is performed on an industrial scale - and the material is highly radioactive - radionuclide separations that are reproducible, predictable, simple and amendable to safe operations are desirable $[2,3]$.

One of the most common techniques employed for this application is liquid-liquid extraction. Liquid-liquid extraction utilizes a biphasic reaction system comprising an aqueous phase (acidic or basic, to insure the metal solubility), and an immiscible organic phase containing an organic-soluble extractant, which displays affinity toward the specific metal 
or radiometal of interest [5-7]. Final isolation of radionuclides and non-radioactive metals may also involve a 'back extraction' (stripping) from the initial organic phase to an aqueous phase by use of a water-soluble extractant [7]. Thus, by utilizing rules of solubility and chemical speciation, solvent extraction parameters can be adjusted to extract particular metals and radiometals from the bulk liquid-waste [4]. To the first approximation, the most important parameters for an efficient separation and isolation of a desired radionuclide or stable metal are the $\mathrm{pH}$, the concentration and properties of the counter-ion (i.e. $\mathrm{Cl}^{-}, \mathrm{NO}_{3}^{-}$), and the identity of the extractant (i.e. 2,6-dimethyl-4-heptanol) [8].

One element of particular interest to the nuclear fuel cycle is protactinium $(\mathrm{Pa})[9,10]$. Although the molar concentration of $\mathrm{Pa}$ in nuclear fuel is generally low, two isotopes have sufficiently long half-lives to be present in appreciable quantities (in terms of radioactivity) in nuclear materials: ${ }^{231} \mathrm{~Pa}\left(t_{1 / 2}=3.28\right.$ $\times 10^{4}$ years $)$ and ${ }^{233} \mathrm{~Pa}\left(t_{1 / 2}=26.98\right.$ days $)$ [11]. For example, in the production of conventional ${ }^{235} \mathrm{U}$ fuel, uranium ore $\left(0.7 \%{ }^{235} \mathrm{U}, 99.3 \%{ }^{238} \mathrm{U}\right)$ is isotopically enriched in ${ }^{235} \mathrm{U}$ up to $5 \%$ [2]. Because ${ }^{231} \mathrm{~Pa}$ is the direct (and longest lived) decay product of ${ }^{235} U$, the enrichment process can result in enhanced ${ }^{231} \mathrm{~Pa}$ radioactivity in waste streams as a result of chemical preconcentration, and its decrease in the ${ }^{235} \mathrm{U}$ fuel, followed by a slow ingrowth of the radioactivity over a long periods of time [12]. While ${ }^{231} \mathrm{~Pa}$ is not likely to exist in significant mass quantities in the nuclear fuel, ${ }^{231} \mathrm{~Pa}$ plays unique roles in the nuclear fuel cycle. Due to its relatively high neutron cross section, ${ }^{231} \mathrm{~Pa}$ can generate fissile isotopes ${ }^{232} \mathrm{U}$ and ${ }^{233} \mathrm{U}$, which can improve core performance and longevity [13-15]. Also, in considering long-term geological repository for spent nuclear fuel, ${ }^{231} \mathrm{~Pa}$ and its shorter-lived daughters (i.e. ${ }^{227} \mathrm{Ac}$ ) will be major contributors to the total radioactivity after $10^{5}$ years $[16,17]$. Likewise, the shorter-lived isotope, ${ }^{233} \mathrm{~Pa}$, will be present in the nuclear fuel cycle as an immediate decay product of neptunium-237 $\left({ }^{237} \mathrm{~Np}\right)$, which can originate from several neutron capture and radioactive decay pathways [18]. Furthermore, ${ }^{233} \mathrm{~Pa}$ has a unique role in alternative fuels cycles, specifically the thorium (Th) fuel cycle $[9,19]$. In the Th fuel cycle, natural, fertile ${ }^{232} \mathrm{Th}$ is neutron--irradiated to form the fissile ${ }^{233} \mathrm{U}$ fuel. In this process ${ }^{233} \mathrm{~Pa}$ is an intermediate, formed by neutron capture, ${ }^{232} \mathrm{Th}(\mathrm{n}, \gamma)^{233} \mathrm{Th}$, and subsequent $\beta^{-}$decay of ${ }^{233} \mathrm{Th}$. The isolation of ${ }^{233} \mathrm{~Pa}$ from other products formed during the irradiation of ${ }^{232} \mathrm{Th}$, could provide near isotopically pure ${ }^{233} U[9,19]$.

While these examples demonstrate the need for an understanding of $\mathrm{Pa}$ extraction from spent nuclear fuel, relatively little is known about the chemistry of $\mathrm{Pa}$, and hence its neglect in most (if not all) industrial separation schemes [8]. Research to understand the chemistry of Pa has traditionally been limited due to challenges in obtaining sufficient quantities of $\mathrm{Pa}$ to perform spectroscopy. However, much can be learned about the chemical behavior of $\mathrm{Pa}$ through observation of its behavior in chemical extraction systems at trace levels $[5,9,20,21]$. Pre-<smiles>CC(C)CC(O)CC(C)C</smiles>

Fig. 1. Structure of 2,6-dimethyl-4-heptanol, common name diisobutylcarbinol or DIBC.

vious research has suggested that aliphatic alcohols can effectively extract and separate Pa from the other actinides and fission products $[5,21]$. Interestingly, an aliphatic alcohol (octanol) is used as a diluent in some separation and extraction systems, suggesting that Pa might be unintentionally extracted at various separation steps [22].

Whether research is occurring in industry, academia, or government, the experimental efficiency and careful planning are essential to ensure safe operations, while meeting financial and extraction objectives. Thus, identifying the ideal parameter settings for a given radiometal extraction in a minimum number of experimental runs is desirable. One approach to experimental design that is used often to improve the efficiency in data collection and interpretation is referred to as the full-factorial design. Full-factorial experimental designs can be developed to maximize experimental information obtained, while minimizing the number of experimental runs required to obtain that information [23, 24]. In addition to identifying the main effects of changes in important experimental parameters, the approach also allows for the identification of effects of two-way and three-way interactions between the reactants. This study aims to apply a full-factorial design to broaden the understanding of the behavior of $\mathrm{Pa}$ in a liquid-liquid extraction system with 2,6-dimethyl-4-heptanol (diisobutylcarbinol; DIBC; Fig. 1) as the extractant in both hydrochloric $(\mathrm{HCl})$ and nitric acid $\left(\mathrm{HNO}_{3}\right)$ systems. To achieve this aim, we investigated this system based upon three extraction parameters: $\left[\mathrm{H}^{+}\right],[\mathrm{DIBC}]$, and [anion $\left(\mathrm{A}^{-}\right) ; \mathrm{Cl}^{-}$or $\left.\mathrm{NO}_{3}^{-}\right]$. We further aimed to develop the understanding of the effect of two-way and three-way interactions between $[\mathrm{DIBC}],\left[\mathrm{H}^{+}\right]$, and $\left[\mathrm{A}^{-}\right]$ on the extraction of $\mathrm{Pa}$ into the organic phase. In addition, our studies were conducted to use the statistical data generated from these experiments to create a mathematical model for the extraction system that can be used to predict $\mathrm{Pa}$ extraction using the DIBC/acid liquid-liquid extraction system.

\section{Experimental}

\section{General}

All chemical regents were ACS Reagent grade (Fisher Scientific, Pittsburg, PA) or higher. These reagents included $\mathrm{HCl}, \mathrm{HNO}_{3}$, sodium chloride $(\mathrm{NaCl})$, and sodium nitrate $\left(\mathrm{NaNO}_{3}\right)$. The organic solvents, dodecane and DIBC, were Sigma-Aldrich (St. Louis, $\mathrm{MO}$ ). Radioactivity standards of ${ }^{233} \mathrm{~Pa}$ were prepared using ultra-pure $\mathrm{HCl}$ (Fisher Scientific) and diluted using ultra-pure distilled deionized water (Baseline ${ }^{\circledR}$, 
Seastar Chemicals, British Columbia, Canada), both were certified to parts-per-trillion metals content. Half-lives and gamma-ray energies values were obtained from the Evaluated Nuclear Structure Data File (ENSDF) through the United States National Nuclear Data Center (NNDC, Brookhaven National Laboratory, US Department of Energy) [11]. All statistical information was generated by Design-Expert ${ }^{\circledR}$ software (Stat-Ease, Inc., Minneapolis, MN). Stated uncertainties are 'standard uncertainties', corresponding to a coverage factor $k=1$ (unless explicitly stated otherwise) and are estimated based on methodologies adherent to national and international standards bodies [25].

\section{Safety considerations}

Radioactive materials are potentially hazardous. Appropriate ALARA principles should be considered prior to conducting experiments with radioactive materials. ${ }^{233} \mathrm{~Pa}$ and ${ }^{237} \mathrm{~Np}$ are radioactive and should only be used in facilities designed to handle radioactivity.

\section{Protactinium-233 standard source}

Since ${ }^{233} \mathrm{~Pa}$ has a relatively short $t_{1 / 2}$, activity standards must be prepared from a ${ }^{237} \mathrm{~Np}$ standard solution via ingrowth of ${ }^{233} \mathrm{~Pa}[21,26,27]$. A nominal standard solution of containing $37 \mathrm{kBq}$ of ${ }^{237} \mathrm{~Np}$ (Lot \#1760-91) used for this study was purchased from the Eckert and Ziegler Radioisotopes (Atlanta, GA, USA) and diluted to working solutions as described by us previously $[21,28]$.

For these studies, ${ }^{233} \mathrm{~Pa}$ was extracted from the working solution of ${ }^{237} \mathrm{~Np}$ using a method described by us previously, which employs an extraction chromatographic resin (Amberchrom CG-71ms, $50-100 \mu \mathrm{m})$ impregnated with of 1-octanol [21]. Briefly, a slurry was prepared of the 1-octanol resin beads $\left(0.66 \mathrm{~g} / 5 \mathrm{~mL} \mathrm{H}_{2} \mathrm{O}\right)$, then a column was prepared by transferring the resin slurry $(5 \mathrm{~mL})$ to an empty plastic column $(0.8 \mathrm{~cm}$ inner diameter $)$. Prior to isolation of ${ }^{233} \mathrm{~Pa}$ from ${ }^{237} \mathrm{~Np}$, the column was preconditioned $(6 \mathrm{M} \mathrm{HCl})$ with several column volumes. Following the column preparation, the ${ }^{237} \mathrm{~Np}$ solution $\left(15 \mathrm{~mL}\right.$; containing $\left.{ }^{233} \mathrm{~Pa}\right)$ was added to the column, and the eluent containing ${ }^{237} \mathrm{~Np}$ was collected for future use. Additional rinses $(2 \times 15 \mathrm{~mL} 6 \mathrm{M} \mathrm{HCl})$ were also collected and combined for future use of the ${ }^{237} \mathrm{~Np} .{ }^{233} \mathrm{~Pa}$ was next eluted from the column $(15 \mathrm{~mL}$ of $1 \mathrm{M} \mathrm{HCl})$ and collected in a separate Teflon beaker. The final activity of the ${ }^{233} \mathrm{~Pa}$ solution was $\sim 0.75 \mathrm{kBq} / \mathrm{mL}^{-1}$.

\section{Experimental engineering and solvent extraction}

The design of experiments was based upon the mathematical principle for maximizing information while minimizing the number of individual experiments by a full factorial design [23, 24]. The computer software Design-Expert $\AA$ was used to design experiments, and the range of experimental parameters were based upon a linear approximation in design space of the extraction of Pa by DIBC at a range of concentrations $[5,29]$. The goal was to determine the main effects of changes in $\left[\mathrm{H}^{+}\right],\left[\mathrm{A}^{-}\right.$, $\mathrm{Cl}^{-}$or $\mathrm{NO}_{3}^{-}$, and [DIBC], as well as the effect of two-way and three-way interactions between the reactants on extraction of $\mathrm{Pa}$ into the organic phase, and finally, develop a predictive mathematical model of the extraction of $\mathrm{Pa}$. The resulting full factorial design provides an estimation of these effects on the distribution coefficient (D) of Pa (Eq. (1)). Each parameter was assigned a low setting $(-)$, a high setting $(+)$, and a midpoint that exists between the - and + to account for curvature in response. The settings chosen for each parameter were determined based upon previous experiments [5, 9]. Based upon these results, a linear approximation was applied, in which the region of interest selected represented the section of the extraction line where the slope was considered steep, linear and where the end points represented the change from poor to satisfactory extraction of $\mathrm{Pa}$ into the organic phase. In $\mathrm{HCl}$, the parameters were $\left[\mathrm{H}^{+}\right] 4-5 \mathrm{M},\left[\mathrm{Cl}^{-}\right] 5-5.5 \mathrm{M},[\mathrm{DIBC}]$ 0.5-1 M. In $\mathrm{HNO}_{3},\left[\mathrm{H}^{+}\right]$1-3 M, $\left[\mathrm{NO}_{3}^{-}\right]$3-4 M, and [DIBC] 0.5-1 M (Fig. 2).

Each solvent extraction system consisted of $5 \mathrm{~mL}$ aqueous phase and $5 \mathrm{~mL}$ organic phase in a $15 \mathrm{~mL}$ plastic conical centrifuge tube. The aqueous phase consisted of the appropriate $\left[\mathrm{H}^{+}\right]$from acid $(\mathrm{HCl}$ or $\mathrm{HNO}_{3}$ ) and $\left[\mathrm{A}^{-}\right]$by the addition of $\mathrm{NaCl}$ or $\mathrm{NaNO}_{3}$. The organic phase contained the appropriate [DIBC] in a dodecane diluent. To the system, $100 \mu \mathrm{L}$ of ${ }^{23} \mathrm{~Pa}$ standard solution $(\sim 75 \mathrm{~Bq})$ was added, and the contents were mixed for 1 hour and allowed to stand for 10 minutes or until the phases separated. Once biphasic conditions were reached, $4 \mathrm{~mL}$ of the organic phase and $4 \mathrm{~mL}$ of the aqueous phase were carefully withdrawn and transferred to separate vials and analyzed by gamma spectroscopy for the activity in the organic and aqueous phases, respectively. The D values were calculated (Eq. (1)) and served as response inputs to the Design-Expert 9 software for further statistical analysis and model generation.

$$
\mathrm{D}=\frac{\text { activity } \mathrm{Pa}_{\text {organic }}}{\text { activity } \mathrm{Pa}_{\text {aqueous }}}
$$

\section{Gamma spectrometry}

The organic and aqueous phases were analyzed separately by gamma-ray spectrometry with a well-type sodium iodide (NaI) detector and spectra were obtained using the gamma spectrometry multi-channel analysis software Maestro (ORTEC, Oak Ridge, TN). Each sample was counted (500 s) and normalized with a match-count-time background spectrum. The count-rate of the sample was calculated by dividing the background-corrected total counts by the dead-time adjusted count-time (500 s). The region of interest for the ${ }^{233} \mathrm{~Pa}$ activity was centered around the $311 \mathrm{keV}$ gamma emission [11]. Activity balance 
verification was performed with a vial containing the ${ }^{233} \mathrm{~Pa}$ standard $(100 \mu \mathrm{L}$ in $4 \mathrm{~mL})$ of an aqueous phase and an organic phase. The geometry of each sample remained identical; resulting in identical detector efficiency for all samples to determine D values. For each sample, both phases were counted sequentially to minimize the effect of radioactive decay of ${ }^{233} \mathrm{~Pa}$. In the time required to count both phases, only $0.04 \%$ of ${ }^{233} \mathrm{~Pa}$ would have decayed. Thus, decay during counting corrections are considered negligible and were not applied.

\section{Results and discussion}

\section{General}

Extraction of ${ }^{233} \mathrm{~Pa}$ by DIBC in both $\mathrm{HCl}$ and $\mathrm{HNO}_{3}$ was performed based on a full-factorial design to generate a model that describes the effect of changes in $\left[\mathrm{H}^{+}\right],[\mathrm{DIBC}]$, and $\left[\mathrm{A}^{-}\right]$on the extraction of $\mathrm{Pa}$ (Fig. 2, Table 1). Previous studies have summarized the extraction of Pa by DIBC by sweeping the $[\mathrm{HCl}]$ and $\left[\mathrm{HNO}_{3}\right]$ to gain an applied understanding of the behavior of Pa in extraction systems [5, 9], this study aims to understand the effects of the experimental parameters and the development of a mathematical model.

Results of the experiments were recorded by the coded independent variable identity (+ or - ) and the response ( $\mathrm{D}$ value). With three independent variables, there were 9 experimental runs $\left(2^{3}+1=\right.$ 9 combinations including the midpoint). Each set of experiments was performed in duplicate to obtain an experimental estimate of the reproducibility of the experiments and increase the power of the model. The results of each of the experimental scenario are summarized in Table 1, where the coded setting (- or $+)$ is shown with the experimental concentration values and the response $D$ values. The midpoint values were included as well to identify curvature that exists with the $\mathrm{D}$ values and each of the independent parameters, as described previously [24].

\section{Distribution coefficients}

The $\mathrm{D}$ values were determined at each point of the experimental cube (Table 1), where the ID represents the experimental concentrations of each parameter. In the chloride scenario, D increases as the parameters shift from low to high concentrations settings, where the average $\mathrm{D}$ values range from $0.18 \pm 0.01$ at $(---)$ to $5.21 \pm 0.62$ at $(+++)$. In the nitrate scenario, D generally increases as the experimental parameters shift from low to high concentrations, but the effects are not as dramatic as those in the chloride system. The $\mathrm{D}$ values range from $0.12 \pm$ 0.00 at $(---)$ to $1.20 \pm 0.04$ at $(+++)$ experimental conditions. While the extraction of $\mathrm{Pa}$ into the organic phase $(\mathrm{D}>1)$ in $\mathrm{HNO}_{3}$ occurs from less concentrated solutions $\left(\sim 2-3 \mathrm{M} \mathrm{HNO}_{3}\right)$ than $\mathrm{HCl}(\sim 4-5 \mathrm{M} \mathrm{HCl})$, the extent of the extraction in $\mathrm{HCl}$ results in much larger $\mathrm{D}$, which corresponds to

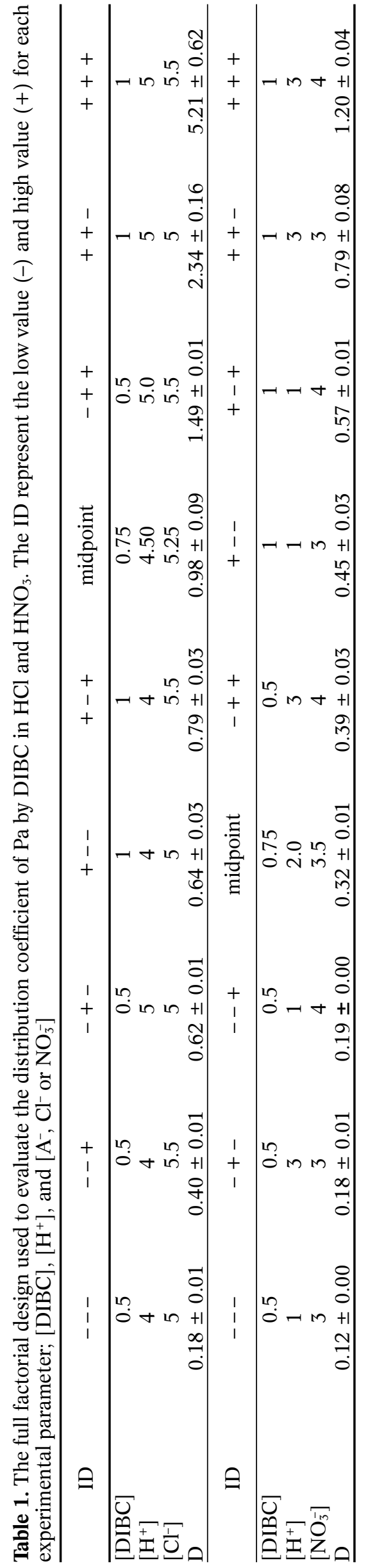


A.

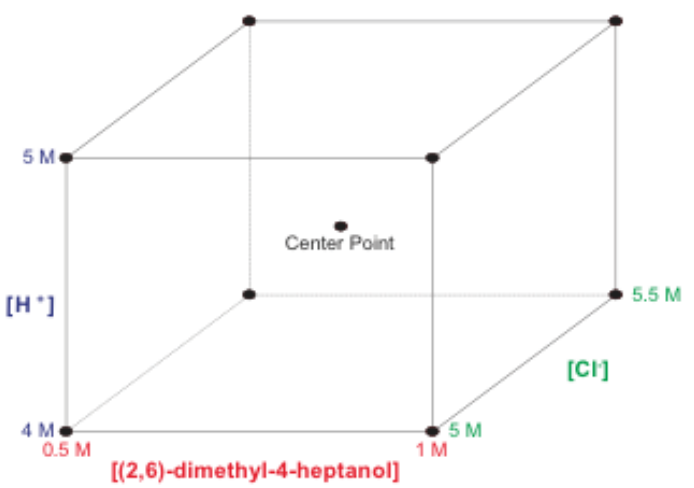

B.

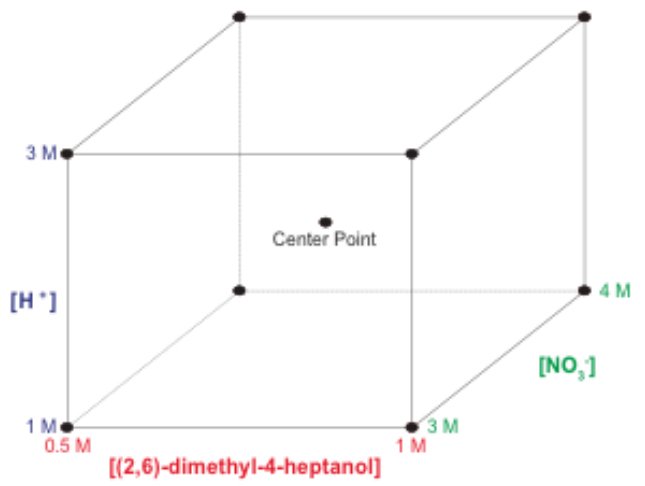

Fig. 2. (A) Full factorial experimental design measuring the $\mathrm{D}$ as a function of $\left[\mathrm{H}^{+}\right],[\mathrm{DIBC}]$, and $\left[\mathrm{Cl}^{-}\right]$. The parameter ranges in chloride system were: $\left[\mathrm{H}^{+}\right]=4-5 \mathrm{M},[\mathrm{DIBC}]=0.5-1 \mathrm{M}$, and $\left[\mathrm{Cl}^{-}\right]=5-5.5 \mathrm{M}$. (B) The same for nitrate system: $\left[\mathrm{H}^{+}\right]=1-3 \mathrm{M},[\mathrm{DIBC}]=0.5-1 \mathrm{M}$, and $\left[\mathrm{NO}_{3}^{-}\right]=3-4 \mathrm{M}$. Each solid black dot represents an experimental data point performed in duplicate; were each vertex was measured as well as a center point to gain information regarding the curvature of the model.

the stronger complexing tendency with $\mathrm{C}$ than with nitrate with respect to $\mathrm{Pa}$ [5]. Furthermore, while the extracted species of $\mathrm{Pa}$ are not fully agreed upon, research suggests that under the conditions explored here, the Pa-chloro complexes extracted into the organic phase have been identified as cations; $\mathrm{PaO}^{3+}$ [30], $\mathrm{Pa}(\mathrm{OH})_{2}^{3+}[30], \mathrm{Pa}(\mathrm{OH}) \mathrm{Cl}_{3}^{+}[31]$, neutral complexes; $\mathrm{Pa}(\mathrm{OH}) \mathrm{Cl}_{4}[31], \mathrm{Pa}(\mathrm{OH})_{2} \mathrm{Cl}_{3}$ [31] or anions; $\mathrm{PaOCl}_{4}^{-}[30,32], \mathrm{Pa}(\mathrm{OH})_{2} \mathrm{Cl}_{4}^{-}[30]$. And in nitrate media, neutral complexes; $\mathrm{Pa}(\mathrm{OH})_{2}\left(\mathrm{NO}_{3}\right)_{3}$ [33], or anions; $\left(\mathrm{Pa}(\mathrm{OH})_{2}\left(\mathrm{NO}_{3}\right)_{4}^{-}\right)[9,33,34]$. Future work in our laboratory aims to identify the extracted species of $\mathrm{Pa}$ by aliphatic alcohols extractants in both $\mathrm{HCl}$ and $\mathrm{HNO}_{3}$.

\section{Data transformation and main effects}

For further statistical analysis to be performed by the software engine, a $\log _{10}$ transformation was necessary because the $\max / \min \geq 10$ of $\mathrm{D}$ responses. The Pereto chart (Fig. 3) summarizes the main effects that each independent variable has on D.

Interestingly, in chloride medium, in addition to the main effect of each experimental parameter, there were variable-interaction effects (three two-variable and a three-variable interaction), which were statistically significant (Bonferroni limit and $t$ value significance levels were 3.46 and 2.26 , respectively). Note, for this experiment, interactions were considered significant when the $t$ value effect was larger than the Bonferroni limit [35]. The largest effect on $\mathrm{D}$ resulted from the $\left[\mathrm{H}^{+}\right]$followed by [DIBC] and $\left[\mathrm{Cl}^{-}\right]$. This suggests that the formation dominant extracted species of Pa was most strongly dependent on the acidity of the solution and not the counterion concentration. These findings correspond with previous investigations, in which it was demonstrated that the extracted species, $\mathrm{PaOCl}_{4}^{-}$by $\mathrm{DIBC}$ becomes the dominant species as [ $\mathrm{HCl}]$ is increased from 3 to $6 \mathrm{M}$ [32], however it was unclear from this study if the formation of $\mathrm{PaOCl}_{4}^{-}$was more strongly dependent on $\left[\mathrm{Cl}^{-}\right]$or $\left[\mathrm{H}^{+}\right]$. Interestingly, our findings would suggest that the formation of the extractable species of Pa can be controlled, given sufficient $\left[\mathrm{Cl}^{-}\right]$ and [DIBC], by solution acidity. Furthermore, the small, but statistically significant, effects of the 2and 3-variable terms appear to contribute synergistic (or anti-synergistic) effects between the DIBC, $\mathrm{Cl}^{-}$, and $\mathrm{H}^{+}$; all having a fairly equal contribution to $\mathrm{D}$. The Pereto chart of the model suggests that the ef-

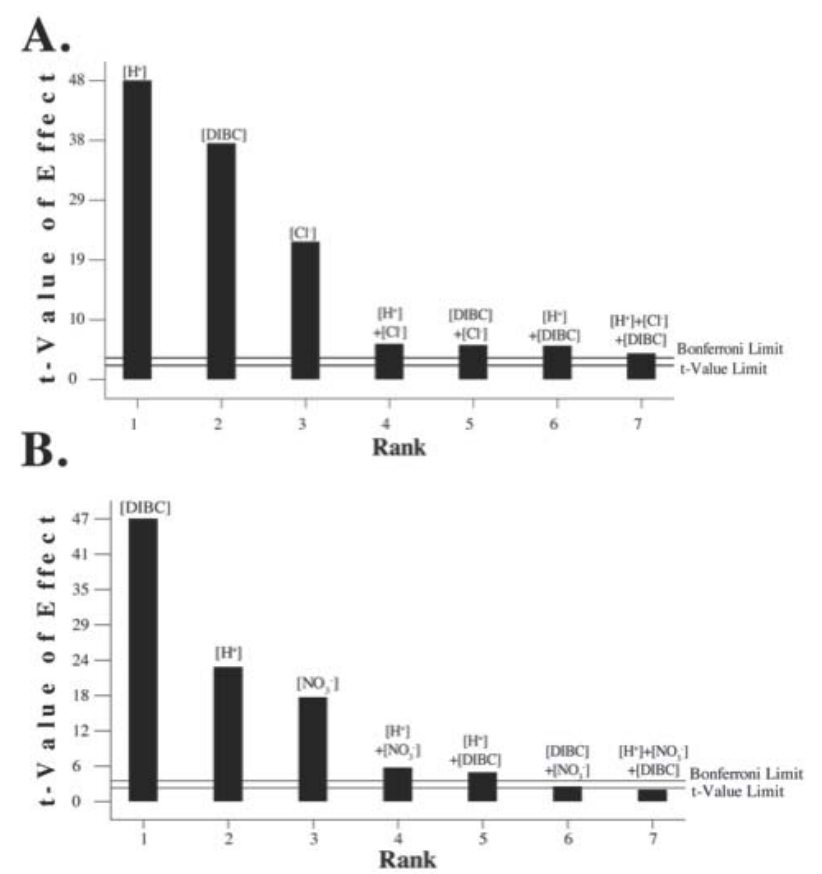

Fig. 3. (A) The Pereto chart demonstrates the main effects on the Pa extraction by DIBC in chloride. In chloride all three main effects, all three 2-factor interactions, and the 3 -factor interaction were greater than the Bonferroni meaning they are statistically significant and affect $\mathrm{D}$. The most significant effect was $\left[\mathrm{H}^{+}\right]$suggesting that the dominant extracted species forms when solution is acidic enough. (B) The Pereto chart of the main effects on the Pa extraction by DIBC in nitrate. In nitrate, the three main effects, and two 2 -factor interactions were greater than the Bonferroni limit and meaning they are statistically significant. The parameter with the largest effect on D was [DIBC]. 
fect of a small change in one experimental parameter cannot be fully predicted without propagating that change through the combination effects.

In the nitrate, the main effects on $\mathrm{D}$ were caused by the [DIBC] followed by the $\left[\mathrm{H}^{+}\right]$then $\left[\mathrm{NO}_{3}^{-}\right]$. The 2- and 3-variable interactions were much weaker than in the chloride system, and only two 2 -variable interaction were statistically significant, $\left[\mathrm{H}^{+}\right]+\left[\mathrm{NO}_{3}^{-}\right]$and $\left[\mathrm{H}^{+}\right]+[\mathrm{DIBC}]$. The remaining 2 -variable interaction and 3-variable interaction effects were below the Bonferroni limit and the $t$ value limit of 3.46 and 2.26, respectively; meaning their effect on the system was not statistically significant. Unlike chloride, in which the main effect on D was most significantly determined by $\left[\mathrm{H}^{+}\right]$, in the nitrate scenario, the main effect was determined by [DIBC]. Therefore, we believe that under the conditions evaluated, the extractable species of $\mathrm{Pa}$ was already the dominant species and D was largely enhanced by the additional of more DIBC to coordinate with the $\mathrm{Pa}$ species $[9,33]$. This assertion is supported by previous studies, in which it was demonstrated that the extractable species $\mathrm{Pa}(\mathrm{OH})_{2}\left(\mathrm{NO}_{3}\right)_{4}{ }_{4}$ formed as the dominant species when the $\left[\mathrm{HNO}_{3}\right]>1 \mathrm{M}$ [36]. These results point to future studies to develop a more detailed understanding of the dominant extractable species of $\mathrm{Pa}$ and conditions under which these species were formed.

\section{Statistical quality of the model}

The data was fit to an unadjusted model (includes the midpoint) to develop the model coefficients. The statistics of the model (Table 2) in chloride (model $\mathrm{F}$ value $=540.5, p<0.0001$ ) and in nitrate $($ model $\mathrm{F}$ value $=195.2, p<0.0001)$ show the overall $F$ value for the models were statistically significant. With these model F values, there is $<0.01 \%$ chance that this could have resulted due to background variation. Therefore, the effect that the variables had on $\mathrm{D}$, and the ability of the model to represent the experimental $\mathrm{D}$ are likely to be a true, and not variations in signal to noise.

The quality of the model was quantified with a lack of fit $\mathrm{F}$ value $(\mathrm{F} *)$, which provides the statistical power to reject the null hypothesis for an alternative one. In chloride system, the model fit the data well $\left(\mathrm{F}^{*}=2.43, p=0.153\right)$, as $\mathrm{F}^{*}$ was not significant. This implies that the uncertainty associated with the model fit was not significant relative to the pure uncertainty, and that there is a $15.3 \%$ chance that the $\mathrm{F}^{*}$ could be produced by variations in the back-

Table 2. Summary of the statistical values describing the quality of the model to reflect the experimental data of the extraction of $\mathrm{Pa}$ by DIBC in both $\mathrm{HCl}$ and $\mathrm{HNO}_{3}$

\begin{tabular}{lcc}
\hline \multicolumn{1}{c}{ Statistical value } & $\mathrm{HCl}$ & $\mathrm{HNO}_{3}$ \\
\hline Model F value & 540.5 & 195.2 \\
Lack of fit F value & 2.43 & 9.64 \\
$\mathrm{R}^{2}$ & 0.9974 & 0.9910 \\
Adjusted R $^{2}$ & 0.9955 & 0.9828 \\
Predicted $\mathrm{R}^{2}$ & 0.9923 & 0.9873 \\
\hline
\end{tabular}

ground measurements. Therefore, $\mathrm{H}_{0}$ can be rejected and the model can be used to evaluate $\mathrm{D}$ of $\mathrm{Pa}$ by DIBC in $\mathrm{HCl}$. While the $\mathrm{F}^{*}$ value is not significant in chloride system, in the nitrate one $\left(\mathrm{F}^{*}=9.64\right.$, $p=0.0036) \mathrm{F}^{*}$ was statistically significant. Where the $p$ value implies that there is only a $0.36 \%$ chance that this $\mathrm{F}^{*}$ could be due to variations in the noise or background of the measurement, which means that the model could fail to successfully represent D based upon input parameters. However, $\mathrm{F}^{*}$ values presented here are calculated directly by the software, which does not take into account the experimental uncertainty. With the experimental uncertainty taken into account, the $\mathrm{F}^{*}$ would likely decrease. Additionally, the range of $\mathrm{D}$ in nitrate system was smaller than in chloride, the system as a whole is less dynamic; therefore equal deviations about the linear regression due to experimental uncertainty will have a much larger effect in nitrate than chloride.

\section{Data correlation and predictability}

The overall goodness of fit of the model to represent the data can be summed up in the $\mathrm{R}^{2}$ values. The values predicted by the model strongly correlate with those in the chloride $\left(\mathrm{R}^{2}=0.9974\right)$ and nitrate systems $\left(\mathrm{R}^{2}=0.9910\right)$. A plot (Fig. 4) demonstrating the correlation between the models and experiments in which predicted $\mathrm{D}$ (calculated from the model) are plotted vs. the experimental D. Because $\mathrm{R}^{2}$ is close to 1 , we can be confident in the ability of the model to be effectively used to understand the extraction of Pa from DIBC within the range of experimental concentrations studied. However, due to the nature of the mathematical determination of $\mathrm{R}^{2}$, as the number of data points increases, $\mathrm{R}^{2}$ may erroneously increase by chance alone, therefore we need to further assess the quality $\mathrm{R}^{2}$ [37].

To better understand how the model fits the experimental results as additional data points are added, the adjusted- $\mathrm{R}^{2}\left(\mathrm{R}_{\text {adj }}^{2}\right)$ can be evaluated [37, 38]. The $\mathrm{R}_{\text {adj }}^{2}$ values are calculated from the $\mathrm{R}^{2}$ but also include terms of sample size $(n=18$ data points; degrees of freedom $=17$ ) and number of regressors ( $p=3$ independent variables), therefore $\mathrm{R}_{\text {adj }}^{2}$ only increases if the new observations improve $\mathrm{R}^{2}$ more than would be expected by chance [37]. After the adjustment, the correlation in chloride $\left(R_{\text {adj }}^{2}=0.9955\right)$ and nitrate $\left(R_{\text {adj }}^{2}=0.9847\right)$ changed very little, which strongly suggest that the quality of the correlation did not increase from additional data points alone, suggesting that there is a true correlation between predicted and experimental data points within the modeled region.

An important property of models is the ability to predict future results. While $\mathrm{R}^{2}$ and $\mathrm{R}_{\text {adj }}^{2}$ measure correlation, a predicted- $\mathrm{R}^{2}\left(\mathrm{R}_{\text {pred }}^{2}\right)$ quantifies the models ability to predict [39]. To calculate a $\mathrm{R}_{\mathrm{pred}}^{2}$, the individual data points are systematically removed, and the regression line is re-determined to assess how well the model fit the removed data point [39]. In the current study, the $\mathrm{R}_{\text {pred }}^{2}$ values for the chloride $\left(\mathrm{R}_{\text {pred }}^{2}=0.9923\right)$ and nitrate $\left(\mathrm{R}_{\text {pred }}^{2}=\right.$ 


\section{A. $\mathrm{HCl}$}

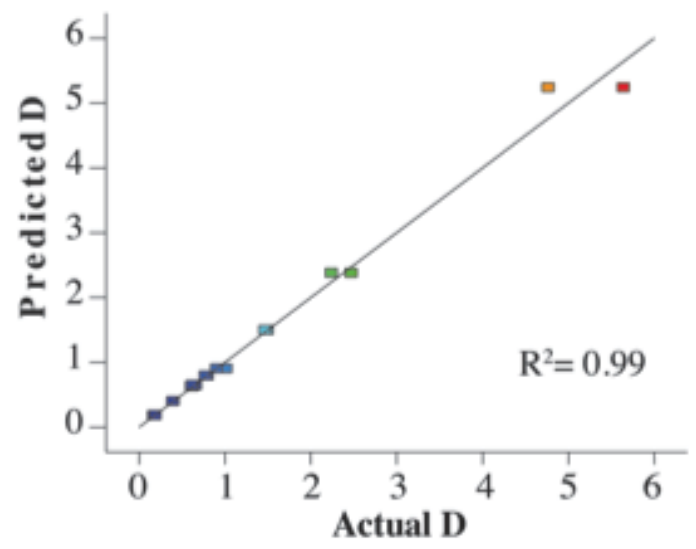

B. $\mathrm{HNO}_{3}^{-}$

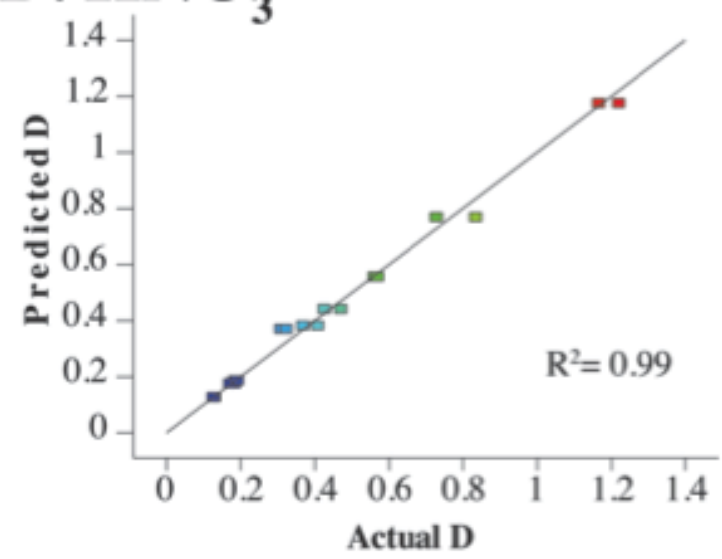

Fig. 4. Plot of the of predicted D vs. the experimental $\mathrm{D}$ values for Pa extraction by DIBC. Plot (A) is in $\mathrm{HCl}$ and (B) is in $\mathrm{HNO}_{3}^{-}$systems. In both cases there is a strong correlation $\left(\mathrm{R}^{2}=0.99\right)$ between predicted and the actual values.

0.9973) are in agreement with the other calculated correlation coefficients $\left(\mathrm{R}^{2}\right.$ and $\left.\mathrm{R}_{\text {adj }}^{2}\right)$ and the $\mathrm{R}_{\text {adj }}^{2}$ is in reasonable agreement $\left(\left|R_{\text {adj }}^{2}-R_{\text {pred }}^{2}\right|<0.2\right)$. Thus, it is reasonable to conclude that the model sufficiently predicts extraction of $\mathrm{Pa}$ by DIBC in $\mathrm{HCl}$ and $\mathrm{HNO}_{3}$ systems when the experimental concentrations of each parameter are within the range of the model.

\section{Mathematical equation of the model}

The model for the extraction of $\mathrm{Pa}$ as a function of the experimental $[\mathrm{DIBC}],\left[\mathrm{H}^{+}\right]$, and $\left[\mathrm{A}^{-}\right]$is represented with respect to $\log _{10} \mathrm{D}$ (Eqs. (2) and (3)).
(2)

$$
\begin{gathered}
\log _{10} \mathrm{D}=-16.182+23.041[\mathrm{DIBC}] \\
+2.255\left[\mathrm{H}^{+}\right]+2.578\left[\mathrm{Cl}^{-}\right] \\
-4.237[\mathrm{DIBC}]\left[\mathrm{H}^{+}\right]-4.440[\mathrm{DIBC}]\left[\mathrm{Cl}^{-}\right] \\
-0.351\left[\mathrm{H}^{+}\right]\left[\mathrm{Cl}^{-}\right]+0.860[\mathrm{DIBC}]\left[\mathrm{H}^{+}\right]\left[\mathrm{Cl}^{-}\right]
\end{gathered}
$$

$$
\begin{gathered}
\log _{10} \mathrm{D}=-2.487+0.968[\mathrm{DIBC}] \\
+2.277\left[\mathrm{H}^{+}\right]+0.306\left[\mathrm{NO}_{3}\right] \\
-0.056[\mathrm{DIBC}]\left[\mathrm{H}^{+}\right]-0.054\left[\mathrm{H}^{+}\right]\left[\mathrm{NO}_{3}^{-}\right]
\end{gathered}
$$

A graphical representation of these equations (Fig. 5) shows the D values plotted as a function of the true concentrations, [DIBC] and $\left[\mathrm{H}^{+}\right]$, at different $\left[\mathrm{A}^{-}\right]$. This representation demonstrates the effect of increasing the $\left[\mathrm{A}^{-}\right]$.
A.

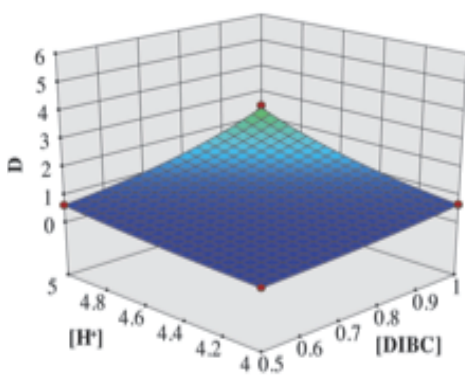

$5.25 \mathrm{M} \mathrm{Cl}$

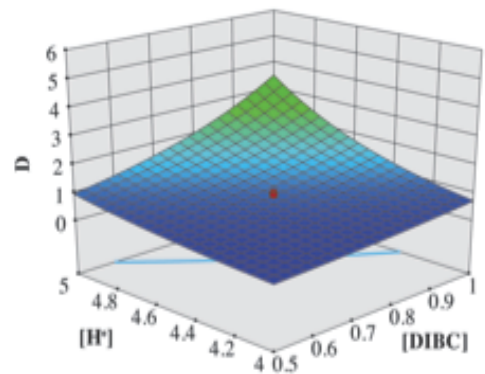

$5.5 \mathrm{M} \mathrm{Cl}^{-}$

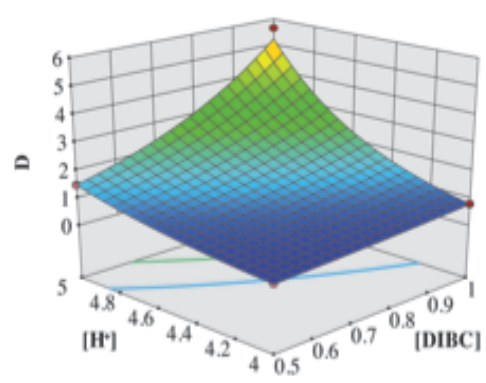

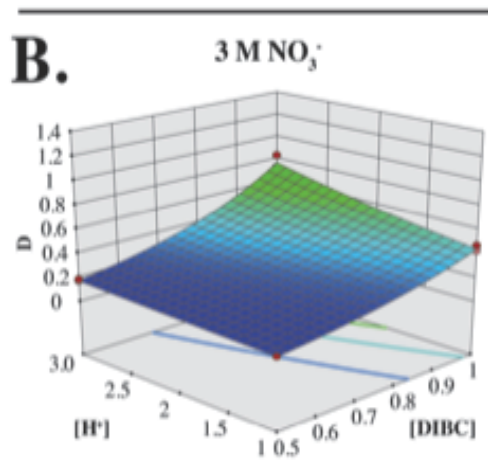

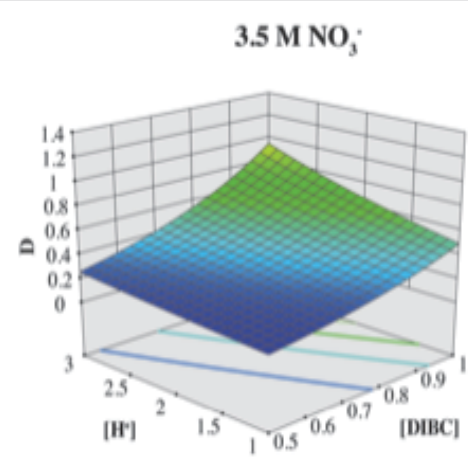

$4 \mathrm{M} \mathrm{NO}_{3}$

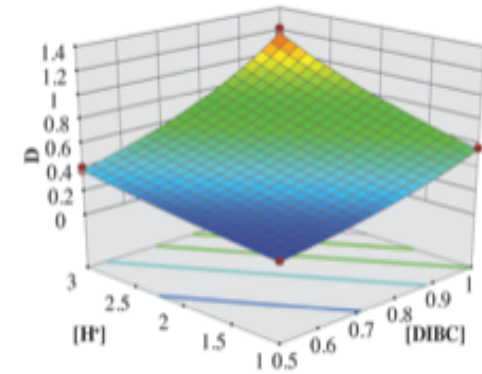

Fig. 5. (A) 3D surface graph plotting the $\left[\mathrm{H}^{+}\right]$and $[\mathrm{DIBC}]$ as a function of $\mathrm{D}$ at three different $\left[\mathrm{Cl}^{-}\right]$. (B) shows a $3 \mathrm{D}$ surface graph plotting $\left[\mathrm{H}^{+}\right]$and $[\mathrm{DIBC}]$ as a function of $\mathrm{D}$ at three different $\left[\mathrm{NO}_{3}^{-}\right]$. The $3 \mathrm{D}$ surface was generated as an extraction model and the dots are the experimental data points. 
While the values of the coefficient cannot be directly correlated to the extracted species stoichiometric relationship to $\mathrm{Pa}$, they can provide an estimation of a quantitative effect of a change to the extraction system. To compare, the coefficients in the chloride are an order of magnitude larger than those in the $\mathrm{NO}_{\overline{3}}^{-}$, reflecting the range of $\mathrm{D}$ in chloride being larger than $\mathrm{D}_{\text {in }} \mathrm{NO}_{3}^{-}$. Additionally, with regards to the y-intercepts; these values represent a control experiment for the extraction of $\mathrm{Pa}$ when [DIBC], $\left[\mathrm{H}^{+}\right]$, and $\left[\mathrm{A}^{-}\right]$are all approximately 0 . In this case, the extraction system contains $5 \mathrm{~mL} \mathrm{H}_{2} \mathrm{O}$ $\left(1 \times 10^{-7} \mathrm{M}^{\circ} \mathrm{H}^{+}\right)$and $5 \mathrm{~mL}$ dodecane. Experimentally, Pa remains fully in the aqueous phase, D $<0.0005$. We would expect that the y-intercept values be near 0 , because the equation is represented in a $\log _{10}$ transformation, the $y$-intercept values for chloride $\left(6.58 \times 10^{-17}\right)$ and $\mathrm{NO}_{3}^{-}\left(3.26 \times 10^{-3}\right)$. In the chloride the $y$-intercept can be considered 0 and therefore the extraction model agrees with the experimental data. In the $\mathrm{NO}_{3}^{-}$, the y-intercept calculated from the model is an order of magnitude larger than the experimentally determined value. While the calculated initial $D$ is near 0 , the model does not appear to fit the data perfect, as we described earlier from a statistically significant $\mathrm{F}^{*}$.

\section{Conclusions and future experiments}

A full-factorial experimental design has been conducted to model the extraction of Pa by DIBC from $\mathrm{HCl}$ and $\mathrm{HNO}_{3}$. The resulting model predicts D of $\mathrm{Pa}$ extraction from these solutions within the range of parameters examined. Using this model, we gain an understanding of how changes in the $[\mathrm{DIBC}],\left[\mathrm{H}^{+}\right]$, and $\left[\mathrm{A}^{-}\right]$effect extraction of $\mathrm{Pa}$ individually, and gain insight on the effect of two-way and three-way variable-interactions. Statistical analysis of the model, suggests that the model may be used to predict future experimental observations that occur within the experimental variable range (Fig. 2). This approach is considered a first step towards a better model of $\mathrm{Pa}$ extraction systems. Future experiments will investigate the identity of the species of Pa extracted by DIBC to gain a more detailed understanding of the chemistry of this extraction system. Based on experimental results presented here, the most effective extraction of Pa by DIBC can be achieved using the following settings: in $\mathrm{HCl}\left(1 \mathrm{M} \mathrm{DIBC}, 5 \mathrm{M} \mathrm{H}^{+}, 5.5 \mathrm{M} \mathrm{Cl}^{-} ; \mathrm{D}=5.21 \pm\right.$ $0.62)$; and in $\mathrm{HNO}_{3}\left(1 \mathrm{M} \mathrm{DIBC}, 3 \mathrm{M} \mathrm{H}^{+}\right.$, and $4 \mathrm{M}$ $\left.\mathrm{NO}_{3}^{-} ; \mathrm{D}=1.20 \pm 0.04\right)$ occur at the high values of each parameter $(+++)$. These results provide a baseline of experimental conditions, which can be used to guide a further optimization of the extraction of $\mathrm{Pa}$ from $\mathrm{DIBC}$ in $\mathrm{HCl}$ and $\mathrm{HNO}_{3}$. Important parameters that are expected to be included in this future work include reaction time, analyte concentration, radiolytic effects, effect of hydrolysis and others.

Acknowledgments. The authors would like to thank Stéphane Bourg and the SACSESS community for the opportunity to share this work. Also the authors would like to thank Nik Barkve for his consultation and expertise in statistical analysis. This work is funded by the U.S. Nuclear Regulatory Commission under grants NRC-HQ-84-14-FOA-0003 and NRC-HQ-12-G-38-0041 and the Department of Homeland Security DHS-DNDO 2012-DN-130-NF0001-02. This material is based upon work supported by the U.S. Department of Homeland Security under Grant Award no. 2012-DN-130-NF0001-02. The views and conclusions contained in this document are those of the authors and should not be interpreted as representing the official policies, either expressed or implied, of the U.S. Department of Homeland Security.

\section{References}

1. King, J.C. (1987). The impact of separation science and technology on some key technological challenges facing society. In R. Price (Ed.), Separation and purification: Critical needs and opportunities. Washington, D. C., USA: National Academy Press.

2. Nuclear Energy Agency with Working Party on Nuclear Criticality Safety and Expert Group on Assay Data of Spent Nuclar Fuel. (2011). Spent nuclear fuel assay data for isotopic validation. Organisation for Economic Co-operation and Development. NEA.

3. International Atomic Energy Agency. (2007). Use of reprocessed uranium. In Technical Committee Meeting. Vienna, Austria: IAEA. (IAEA-TECDOC-CD-1630).

4. Simpson, M. F., \& Law, J. D. (2010). Nuclear fuel reprocessing. Idaho Falls, Idaho: Idaho National Laboratory. (INL/EXT-10-17753).

5. Kirby, H. W. (1959). The radiochemistry of protactinium. National Academy of Sciences National Research Council. (Nuclear Series, NAS-NS 3016).

6. Rydberg, J., Musikas, C., Choppin, G. R., \& Cox, M. (2004). Solvent extraction principles, and practices. 2nd ed. New York: Marcel Dekker.

7. Multi-Agency Radiological Laboratory Analytical Protocols Manual. (2004). 14.4 Solvent Extraction. (NUREG-1576), (EPA 402-B-04-001A), (NTIS PB2004-105421).

8. U. S. Department of Energy. (2011). Nuclear separations technologies workshop report: Getting from where we are to where we want to be in nuclear separations technologies. Bethesda, Maryland.

9. Kumari, N., Pathak, P. N., Prabhu, D. R., \& Manchanda, V. K. (2012). Solvent extraction studies of protactinium for its recovery from short-cooled spent fuel and high-level waste solutions in thorium fuel cycle using diisobutyl carbinol (DIBC) as extractant. Desalin. Water Treat., 38(1/3), 46-51. DOI: 10.5004/ DWT.2012.2292.

10. Rampolla, D. S. (1982). U. S. Patent No. 4,344,912A. Method of increasing the deterrent to proliferation of nuclear fuels. U. S. Department of Energy.

11. National Nuclear Data Center. (2015). Infomation extracted from the NuDat 2 database. http://www. nndc.bnl.gov/nudat2.

12. Eppich, G. R., William, R. W., Gaffney, A. M., \& Schorzman, K. C. (2013). U-235-Pa-231 age dating of uranium materials for nuclear forensic investigations. J. Anal. At. Spectrom., 28(5), 666-674. DOI: 10.1039/C3ja50041a.

13. Trianti, N., Su'ud, Z., \& Riyana, E. S. (2012). Design study of thorium-232 and protactinium-231 based fuel 
for long life BWR. In 3rd International Conference on Advances in Nuclear Science and Engineering. (1448, pp. 96-100).

14. Imamura, T., Saito, M., Yoshida, T., \& Artisyuk, V. (2004). Production of Pa-U fuel with proliferation resistance by $14 \mathrm{MeV}$ neutron for long-life core. $J$. Nucl. Sci. Technol., 40(6), 655-664.

15. Tsvetkov, P. V., Kryuchkov, E. F., Shmelev, A. N., Apse, V. A., Kulikov, G. G., Masterov, S. V., Kulikov, E. G., \& Glebov, V. B. (2011). Isotopic uranium and plutonium denaturing as an effective method for nuclear fuel proliferation protection in open and closed fuel cycles. In P. Tsvetkov (Ed.), Nuclear power-deployment, operation and sustainability (Chapter 14). Winchester, UK: InTech.

16. Myasoedov, B. F., Kirby, H. W., \& Tananaev, I. G. (2010). Protactinium. In L. R. Morss, N. M. Edelstein, \& J. Fuger (Eds.), The chemistry of the actinide and transactinide elements. Vol. 1. Dordrecht, Netherlands: Springer.

17. Berry, J. A., Hobley, J., Lane, S. A., Littleboy, A. K., Nash, M. J., Oliver, P., Smith-Briggs, J. L., \& Williams, S. J. (1989). Solubility and sorption of protactinium in near-field and far-field environments of a radioactive waste repository. Analyst, 114, 339-347.

18. Forbes, T. Z., Burns, P. C., Soderholm, L., \& Skanthakumar, S. (2007). Hydrothermal synthesis and structure of neptunium(V) oxide. In D. Dunn, C. Poinssot, \& B. Begg (Eds.), Scientific basis for nuclear waste management XXX, (Vol. 985, pp. 401-406). Cambridge, UK: Cambridge University Press.

19. De Sio, S. M., \& Wilson, R. E. (2014). Structural and spectroscopic studies of fluoroprotactinates. Inorg. Chem., 53(3), 1750-1755.

20. Eskandari Nasab, M. (2014). Solvent extraction separation of uranium(VI) and thorium(IV) with neutral organophosphorus and amine ligands. Fuel, 116, 595-600.

21. Knight, A. W., Nelson, A. W., Eitrheim, E. S., Forbes, T. Z., \& Schultz, M. K. (2015). A chromatographic separation of neptunium and protactinium using 1-octanol impregnated onto a solid phase support. J. Radioanal. Nucl. Chem. DOI: 10.1007/s10967-015-4124-3.

22. Hill, C. (2010). Overview of recent advances in An(III)/Ln(III) separation by solvent extraction. In B. Moyer (Ed.), Ion exchange and solvent extraction. (A Series of Advances, Vol. 19, pp. 119-193). Boca Raton: CRC Press.

23. Box, G. E. P., Hunter, W. G., \& Hunter, J. S. (1978). Statistics for experimenters: An introduction to design analysis and model building. New York: John Wiley and Sons.

24. Schultz, M. K., Inn, K. G. W., Lin, Z. C., Burnett, W. C., Smith, G., Biegalski, S. R., \& Filliben, J. (1998).
Identification of radionuclide partitioning in soils and sediments: Determination of optimum conditions for the exchangeable fraction of the NIST standard sequential extraction protocol. Appl. Radiat. Isot., 49(9/11), 1289-1293.

25. Currie, L. A. (1968). Limits for qualitative detection and quantitative determination. Anal. Chem., 40(3), 586-593.

26. Burnett, W. C., \& Yeh, C. C. (1995). Separation of protactinium from geochemical materials via extraction chromatography. Radioact. Radiochem., 6(4), 22-32.

27. Regelous, M., Turner, S. P., Elliot, T. R., Rostami, K., \& Hawkesworth, C. J. (2004) Measurement of femtogram quantities of protactinium in silicate rock samples by multicollector inductively coupled plasma mass spectrometry. Anal. Chem., 76(13), 3584-3589.

28. Knight, A. W., Eitrheim, E. S., Nelson, A. W., Nelson, S., \& Schultz, M. K. (2014). A simple-rapid method to separate uranium, thorium, and protactinium for U-series age-dating of materials. J. Environ. Radioact., 134, 66-74.

29. Silva, A., Delerue-Matos, C., \& Fiuza, A. (2005). Use of solvent extraction to remediate soils contaminated with hydrocarbons. J. Hazard. Mater., 124(1/3), 224-229.

30. Scherff, H. -L., \& Herrmann, G. (1966). Ionic species of pentavalent protactinium in hydrochloric acid solutions. Radiochim. Acta, 6(2), 53-61.

31. Casey, A. T., \& Maddock, A. G. (1959). The chemistry of protactinium - some spectrophotometric observations. J. Inorg. Nucl. Chem., 10(1/2), 58-68.

32. Guillaumont, R., Muxart, R., Bouissieres, G., \& Haissinsky, M. (1960). Spectres Dabsorption Du Protactinium En Solution Aqueuse. J. Chim. Phys. Phys.-Chim. Biol., 57(11/12), 1019-1028.

33. Hardy, C. J., Scargill, D., \& Fletcher, J. M. (1958) Studies on protactinium(V) in nitric acid solutions. J. Inorg. Nucl. Chem., 7(3), 257-275.

34. Spitsyn, V. I., \& Dyachkov, R. A. (1964). Concentrating ${ }^{231} \mathrm{~Pa}$ from uranium production waste. J. Nucl. Energy $A B, 18(12 \mathrm{PA}), 731$.

35. Hochberg, Y., \& Tamhane, A. C. (1987). Multiple comparison procedures. New York: Wiley.

36. Spitsyn, V. I., Dyachkov, R. A., \& Khlebnikov, V. P. (1964). State of protactinium in nitrate solutions. Dokl. Akad. Nauk SSSR, 157(1), 135-138.

37. Theil, H. (1971). Principles of econometrics. New York: John Wiley \& Sons.

38. Theil, H. (1961). Economic forecasts and policy. 2nd ed. Amsterdam: North-Holland Publ. Co.

39. Anderson, M. J., \& Whitcomb, P. J. (2007). DOE Simplified: Practical tools for effective experimentation. New York: Productivity. 